AperTO - Archivio Istituzionale Open Access dell'Università di Torino

\title{
Chondrosarcoma of the TMJ: a case report and review of the literature
}

\section{This is the author's manuscript}

Original Citation:

Availability:

This version is available http://hdl.handle.net/2318/69460

since

Published version:

DOI:10.1016/j.joms.2009.09.077

Terms of use:

Open Access

Anyone can freely access the full text of works made available as "Open Access". Works made available under a Creative Commons license can be used according to the terms and conditions of said license. Use of all other works requires consent of the right holder (author or publisher) if not exempted from copyright protection by the applicable law. 


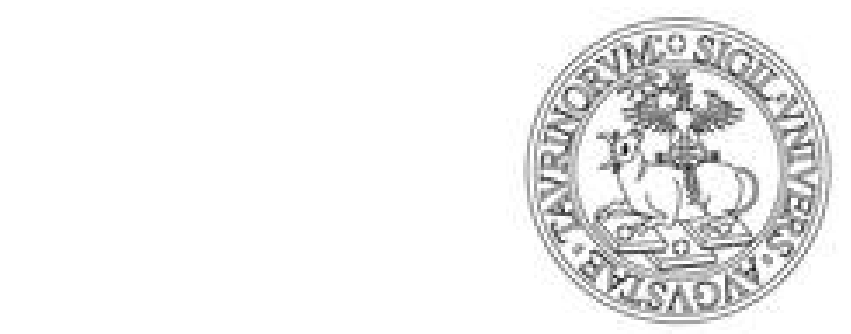

\section{UNIVERSITÀ DEGLI STUDI DI TORINO}

This Accepted Author Manuscript (AAM) is copyrighted and published by Elsevier. It is posted here by agreement between Elsevier and the University of Turin. Changes resulting from the publishing process - such as editing, corrections, structural formatting, and other quality control mechanisms - may not be reflected in this version of the text. The definitive version of the text was subsequently published in JOURNAL OF ORAL AND MAXILLOFACIAL SURGERY, 68, 2010, .

You may download, copy and otherwise use the AAM for non-commercial purposes provided that your license is limited by the following restrictions:

(1) You may use this AAM for non-commercial purposes only under the terms of the CC-BY-NC-ND license.

(2) The integrity of the work and identification of the author, copyright owner, and publisher must be preserved in any copy.

(3) You must attribute this AAM in the following format: Creative Commons BY-NC-ND license (http://creativecommons.org/licenses/by-nc-nd/4.0/deed.en), 


\section{Chondrosarcoma of the Temporomandibular Joint: A Case Report and Review of the Literature}

Garzino-Demo, Paolo, Tanteri, Giulia, Boffano, Paolo, Ramieri, Guglielmo, Pacchioni, Donatella, Maletta, Francesca, Bianchi, Caterina Chiara, Bianchi, Silvio Diego, Berrone, Sid

Corresponding author:

BoffanoPaolo

Divisione di Chirurgia Maxillo-Facciale, Corso Dogliotti 14, 10126 Torino, Italy

Chondrosarcomas (CHSs) are defined by the World Health Organization as malignant tumors with a pure hyaline cartilage differentiation and are therefore characterized by the formation of cartilage, not bone, originating from neoplastic cells. ${ }^{1}$ and $2 \mathrm{CHSs}$ have been widely reported in the literature and may arise in any region where cartilage is present. ${ }^{3,4,5,6 \text { and } 7}$

Depending on the author, $5 \%$ to $12 \%$ of CHSs are confined to the head and neck region. They represent fewer than $5 \%$ of all tumors in this area and are therefore considered very rare. ${ }^{8,9}$ and ${ }^{10} \mathrm{As}$ reported by Sammartino et al, 49 cases, 14 in India and 35 in Japan, have been described over a period of 50 years. ${ }^{11}$ In a study of 56 maxillofacial CHSs over a period of 65 years, Saito et al listed the involved sites and the percentage of presentation as follows: the maxilla (44.6\%); the nasal septum, the ethmoid, and sphenoid bone (41.1\%); the nose tip (3.6\%); and the mandible $(10.7 \%) .{ }^{12}$ Within the mandible, the main affected areas are those with an enchondral ossification as opposed to those with a membranous ossification (corpus and ramus). ${ }^{13}$ and ${ }^{14}$ This intuitively led to the hypothesis that CHSs may arise from mesenchymal cells or from embryonic remnants of the cartilage matrix. ${ }^{15}$ and 16

CHS of the temporomandibular joint (TMJ) is instead extremely rare. In the literature only 17 cases have been reported to date (Medline 1966-2009, English language only; Table 1). ., 17, 18, 19, 20, 21, 22, 23, 24, 25, 26, 27, 28 and ${ }^{29}$ In this report, the authors present 1 case of condylar CHS along with a review of the existing literature.

Table 1.

Reported Cases of TMJ Chondrosarcoma

\begin{tabular}{|c|c|c|c|c|c|c|c|}
\hline \multirow[b]{2}{*}{$\begin{array}{l}\text { First } \\
\text { Author }\end{array}$} & \multicolumn{4}{|c|}{ Duration } & \multirow[b]{2}{*}{ Imaging } & & \multirow[b]{2}{*}{$\begin{array}{c}\text { Follow- } \\
\text { Up }\end{array}$} \\
\hline & $\begin{array}{c}\text { Gende } \\
\mathbf{r}\end{array}$ & $\begin{array}{c}\text { Ag } \\
\mathbf{e}\end{array}$ & $\begin{array}{c}\text { of } \\
\text { Sympto } \\
\text { ms (mo) }\end{array}$ & $\begin{array}{c}\text { MainComplai } \\
\text { nt }\end{array}$ & & $\begin{array}{cc}\text { Surger } & \text { Irradiatio } \\
\mathbf{y} & \mathbf{n}\end{array}$ & \\
\hline $\begin{array}{l}\text { Gingrass } \\
(1954)^{17}\end{array}$ & $\mathrm{~F}$ & 46 & 12 & Swelling, pain & $\begin{array}{l}\text { Slight TMJ } \\
\text { space } \\
\text { widening, } \\
\text { subcortical } \\
\text { sclerosis }\end{array}$ & $X$ & - \\
\hline $\begin{array}{l}\text { Lanier } \\
(1971)^{18}\end{array}$ & $\mathrm{~F}$ & 48 & 24 & Swelling, pain & $\begin{array}{l}\text { Condylar } \\
\text { resorption }\end{array}$ & $X$ & $\begin{array}{l}\text { Fewmont } \\
\text { hs }\end{array}$ \\
\hline $\begin{array}{l}\text { Richter } \\
(1974)^{19}\end{array}$ & $\mathrm{M}$ & 75 & 10 & Swelling, pain & $\begin{array}{l}\text { TMJ space } \\
\text { widening, } \\
\text { erosion of } \\
\text { the glenoid } \\
\text { fossa, }\end{array}$ & $X$ & $12 \mathrm{~m}$ \\
\hline
\end{tabular}




\section{Duration}

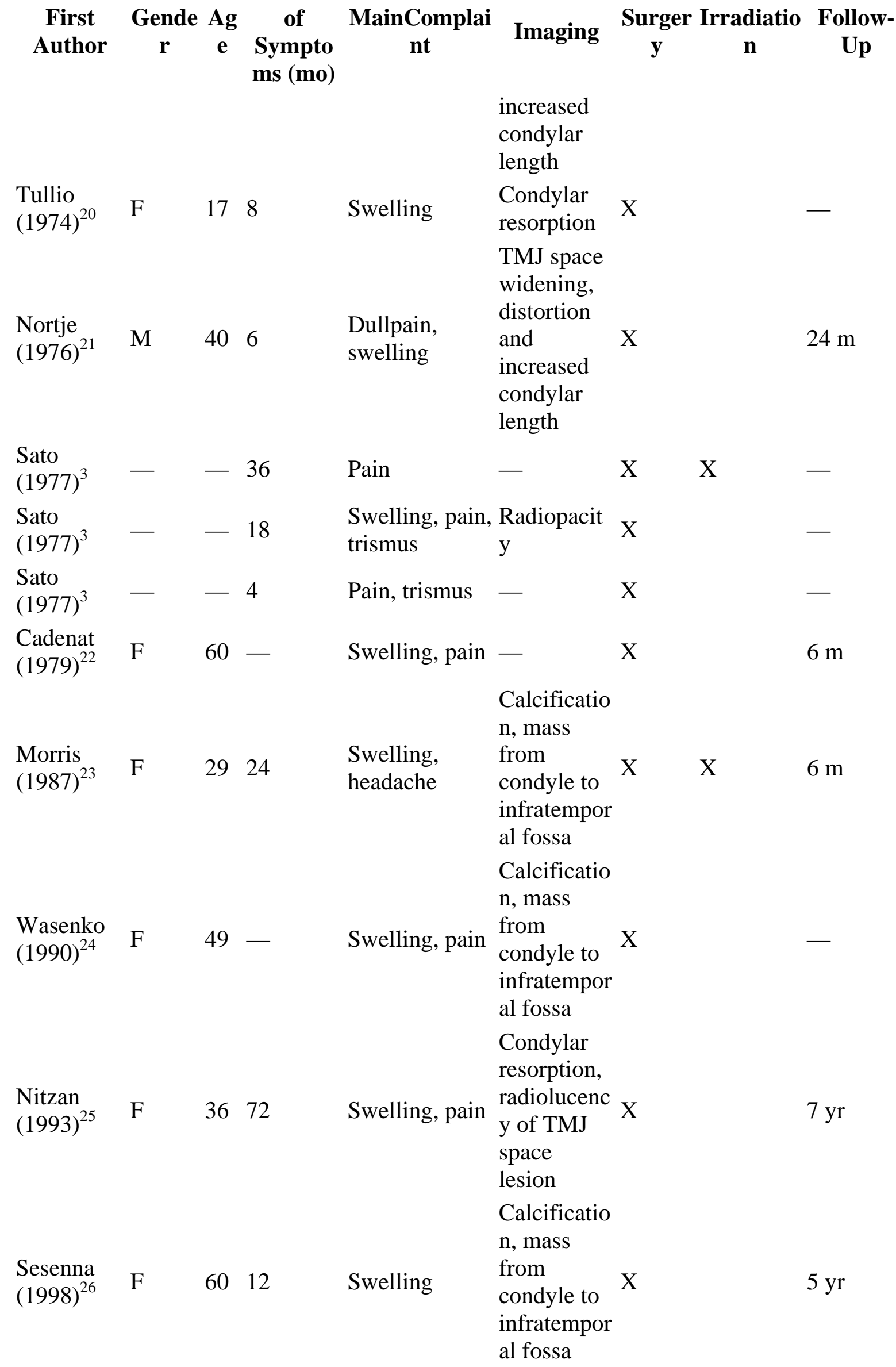




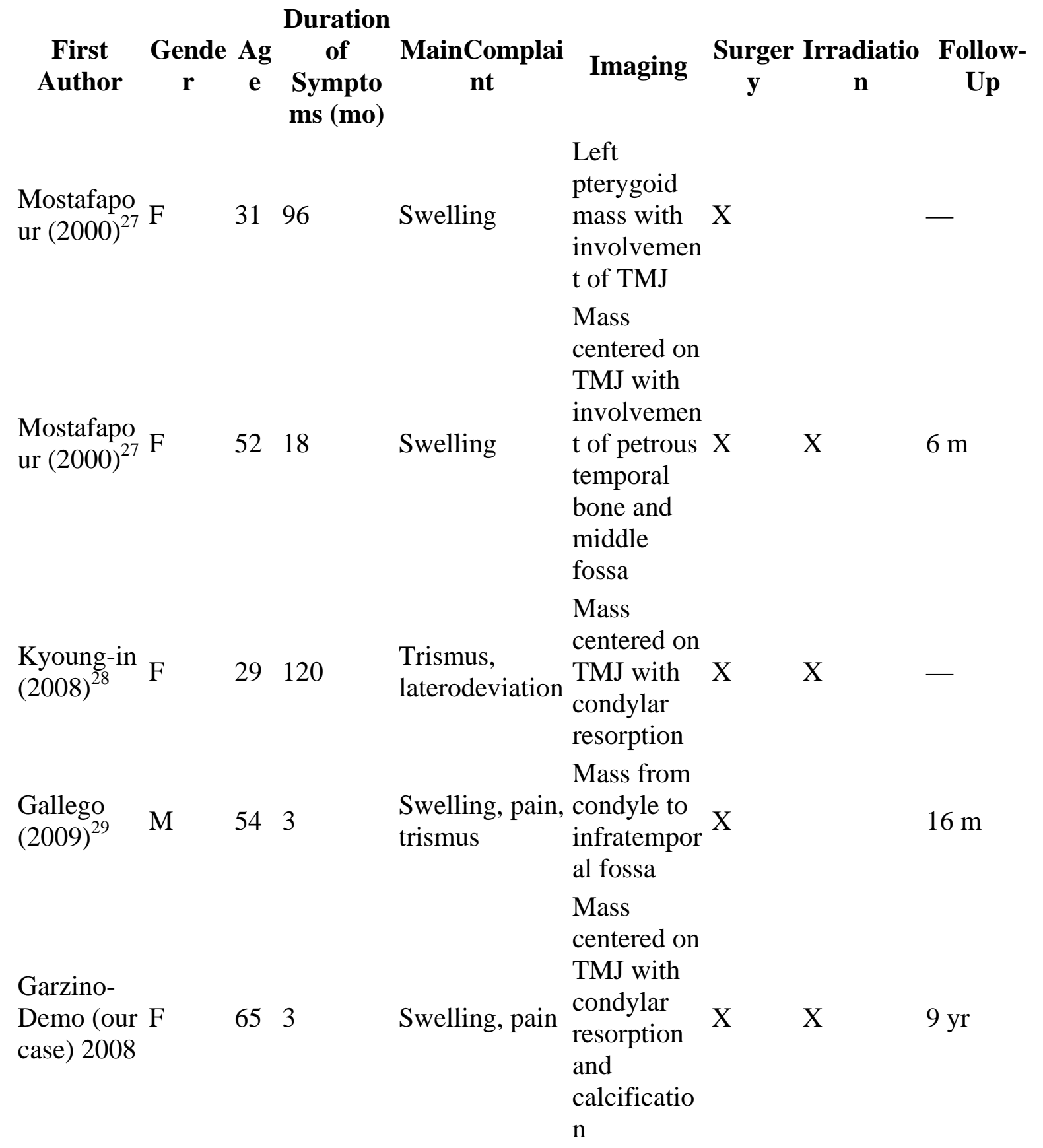

\section{REPORT OF A CASE}

A 65-year-old female patient affected by a hard and painful mass adjacent to the right condyle was referred to the Division of Oral and Maxillofacial Surgery, University of Turin Hospital. The patient mainly complained of persistent swelling and progressive dull pain for the previous 3 months. Clinical examination showed that mouth opening and lateral and protrusive movements were normal.

Panoramic radiography showed osteosclerotic changes of the right condyle, the shape of which was altered from erosion. Amorphous and slightly radiopaque structures were detectable ahead of the condyle (Figure 1 and Figure 2).

Computed tomographic (CT) scan confirmed and better demonstrated osteosclerosis and erosion of the condyle and clearly depicted a nonenhancing mass with mottled calcification surrounding the condyle itself. Such a mass was grossly modeled on the articular capsule in which it appeared to be confined. The overall radiographic appearance suggested the presence of an intra-articular tumor 
with a calcified component due to both bone erosion and new formation of mineralized tissue compatible with CHS (Figure 3 and Figure 4).

An initial ultrasound-guided fine-needle aspiration biopsy (US-FNAB) was inadequate for diagnosis, whereas a second preoperative FNAB led to the diagnosis of a low-grade CHS (Figs 5AC). Although chances of metastasis were slight, a scintigraphy was performed anyway and showed an uptake in the right TMJ region (Fig 6).

Following a superficial parotidectomy and identification of the main branch of the facial nerve, as well as the zygomatic and buccal branches, a wide radical excision with a zygomatic arch osteotomy and a resection of the upper part of the mandibular ramus was performed. All structures of the TMJ---including the articular capsule and disc---were sacrificed with the exception of the glenoid fossa (Figure 7 and Figure 8). An arthroprosthesis with a titanium condyle head was inserted, and the surgical gap was filled at the glenoid fossa with the posterior half of a temporal myofascial flap (Figure 9 and Figure 10). Postoperative histopathological examination confirmed the diagnosis of a grade I CHS (Fig 1D). On the fifth day, the patient was discharged and later received radiation therapy (74 Gy). Nine years elapsed without any sign of recurrence.

\section{DISCUSSION}

The incidence of TMJ neoplasia is very low. In this region, the presentation mode of tumors may mimic those symptoms related to much more frequent pathologies, such as chronic inflammation. In particular, chronic and progressive limitation in mouth opening, swelling, and laterodeviation may be caused by masses such as benign or malignant tumors and synovial chondromatosis.

In a review of TMJ tumor masses, Mostafapour and Futran highlighted an average diagnostic delay ranging from 13 months to 8 years. ${ }^{27}$ Moreover, an initial misdiagnosis is frequent. The authors thus suggest further instrumental investigation in the case of progressive difficulty in mouth opening, laterodeviation, and swelling in the preauricular region lasting for more than 1 month and not responsive to therapy.

Mandibular CHS especially when involving the TMJ, is extremely rare. The molar region and, in descending order, the symphysis and the coronoid process may be involved more frequently. ${ }^{4}$ 13 and 14

CHS may be primitive or secondary depending on whether it develops ex novo or from pre-existing lesions (enchondroma, osteochondroma). It may have an endosseous origin---central CHS---or arise from the periosteum-iuxtacortical CHS. ${ }^{11}$ Only 17 cases of TMJ CHSs have been reported so far in English (Medline 1966 to January 2009). Review of the literature shows that there is a clear prevalence in females (11 of 17 were female, in 3 cases gender was not stated) and this is in conflict with the overall facial skeletal occurrence where the affected males are $60 \%$ and the affected females are $40 \%{ }^{4}$ and 30

The age spectrum ranges from 17 to 75 years (mean, 36.8). The diagnostic delay goes from 3 months to 12 years; this is quite similar to what Mostafapour and Futran reported in their revision of TMJ tumor masses. ${ }^{27}$ The delay is basically due to a misidentification of CHS with TMJ chronic inflammatory pathologies.

The most commonly recognized symptom is a preauricular swelling (14 of 17 cases), followed by spontaneous pain as well as pain during mastication (11 of 17), whereas trismus (4 of 17) and laterodeviation at mouth opening (1 of 17) are quite rare. As Mostafapour and Futran pointed out, CHS is generally more painful than enchondroma. ${ }^{27}$

Conventional radiographs may often afford evidence of chondrosarcoma. Pathognomonic signs are the presence of an irregular erosion of the condyle with calcifications localized within the articular space. However, they do not provide adequate information on the extension of the lesion; therefore, other imaging modalities such as CT or magnetic resonance imaging should be performed to confirm the diagnosis and to complete the preoperative workup. With these techniques a 
nonenhancing mass with flocculent calcification can be seen at the level of the condyle affected, with or without osseous destruction. The mass may contain calcifications, and this was the case in 5 of 17 patients. It may cause deformities ( 2 of 17) and condylar erosions (5 of 17). In most cases an increase in the articular space is observed (10 of 17) as well as an involvement of the extra-articular structures (6 of 17) with an erosion of the glenoid fossa and involvement of the infratemporal fossa along with the temporal bone and the middle cranial fossa.

Performing both magnetic resonance imaging and CT are indicated to achieve the best treatment plan and, although metastatic potential is low on average, scintigraphy can be one further examination to carry out.

Histologically, it is possible to observe the proliferation of hyaline cartilage and the presence of a sarcomatousstroma, which contains star-shaped cells, spindle-shaped cells, and round cells. ${ }^{31}$ Histopathological CHS classification is based on tumor grading. Evans et al classified CHS in 3 separate grades according to the number of mitoses, cellularity, and tumor size. ${ }^{32}$ Grade I shows hypercellularity, chondrocytes with an increased volume, and polymorph hyperchromaticbinucleate forms. Some cases, mostly large lesions, may have a mixoid matrix with foci of calcification. There is a slight to moderate atypia but mitoses are quite rare. Grades II and III show a progressive increase in nuclear polymorphism and the presence of numerous large nuclei.

Cellular differentiation affects metastatic potential. Metastases rates range from $10 \%$ in grade II CHS to $71 \%$ in grade III CHS. No metastases are reported in grade I CHS. ${ }^{26}$ These data are, however, related to bones and joints of other parts of the body.

Local recurrences are instead independent of tumor grading and seem to be related to inadequate previous surgical therapy. ${ }^{26}$

Data concerning TMJ CHSs are not complete because they are not always fully reported and are sometimes lacking information about tumor grading. Also, many authors report intermediate grades between I and III. However, when grading is stated, grade I CHSs appear to be prevalent.

Regarding the diagnostical phase, biopsy of CHS is not advised by some authors because of the risk of anaplastic transformation and diffusion during manipulation of the mass. ${ }^{33}$ and ${ }^{34}$ Moreover, as Morris et al pointed out, FNAB does not always provide a reliable diagnosis. ${ }^{23}$ Here FNAB was initially inadequate for diagnosis but a second cytology actually led to the correct diagnosis, which was then confirmed by conventional histopathological examination. Incisional biopsy is, however, the best option for distinguishing among osteogenic sarcoma, pleomorphic adenoma, and chondroma.

Because of the rarity that maxillomandibular CHS represents, there are no specific treatment protocols outlined. This explains that treatment modalities are the ones that have been previously used for CHS and sarcomas of other regions.

Surgical therapy represents the gold standard for primary treatment of this neoplasm. ${ }^{7}$, ${ }^{36}$ and ${ }^{37}$ Resection must be as wide as possible, and the presence of large healthy tissue margins $(>2$ to $3 \mathrm{~cm}$ ) seems to positively affect prognosis and chances of recurrence. ${ }^{11 \text { and } 36}$

Other treatment modalities include intralesional resection and curettage along with radiation therapy. These modalities are not curative and have been described for large lesions that cannot possibly be treated with surgery only. ${ }^{35}$ and 38

Cryotherapy has been described for grade I lesions. ${ }^{39,40 \text { and } 41}$ This treatment may provide advantages from a functional point of view but not as many from the oncologic one.

In all 17 cases reported in the literature and in the present case, CHS was treated by surgery. In a few cases, surgery implied emimandibulectomy, ${ }^{20}$ and 21 but more frequently a simple condylectomy was performed. ${ }^{23,}{ }^{25}$ and ${ }^{28}$ In more extended cases, such as the ones described by Mostafapour and Futran, surgery consisted of frontotemporal craniotomy and cranial base resection followed by reconstruction with rectus abdominis free flaps. ${ }^{27}$

Although resection seems the surgical technique of choice for maxillomandibular CHSs, a high percentage of recurrence has been described with surgery alone. ${ }^{11}$ Therefore, a combination of surgery and radiation therapy and/or chemotherapy has been proposed. However, results on 
recurrences and survival still appear controversial. Radiation therapy alone is not effective, but its use along with surgery seems to increase survival rate and local control of the disease. More specifically, adjuvant radiation therapy in TMJ CHS has led to a long survival period in 3 of 17 reported cases, and the same holds true for the case presented here as well. ${ }^{14}$ and 32

The choice of not using a complete fossa and condylar head prosthesis was determined by the fact that our patient had to undergo radiation therapy. Our experience with complications due to the presence of metal prosthetic devices in radiotherapeutic patients made us opt for a condylar head prosthesis.

Once again it is important to highlight the fact that survival rates are often not stated and that, although most surgeons actually recommend this sort of therapy, some of their patients may not undergo full treatment for their own personal reasons.

\section{REFERENCES}

1. F. Bertoni, B. Bacchini, P. Hogendoorn

Chondrosarcoma

I. Press (Ed.), World Health Organization Classification of Tumors (2002), pp. 247-258 Lyon

2. F. Schajowicz

Tumors and Tumorlike Lesions of Bone and Joints

Springer-Verlag, New York (1981)

3. K. Sato, H. Nukaga, T. Horikoshi

Chondrosarcoma of the jaws and facial skeleton: A review of the Japanese literature

J Oral Surg, 35 (1977), p. 892

4. W.W. Weiss, J.A. Bennett

Chondrosarcoma: A rare tumor of the jaws

J Oral MaxillofacSurg, 44 (1986), p. 73

5. H.A. Ajagbe, J.O. Daramola, T.A. Junaid

Chondrosarcoma of the jaw: Review of fourteen cases

J Oral MaxillofacSurg, 43 (1985), p. 763

6. A.P. Chaudhry, M.R. Robinovitch, D.F. Mitchell, et al.

Chondrogenic tumors of the jaws

Am J Surg, 102 (1961), p. 403

7. M. Gorsky, J.B. Epstein

Craniofacial osseous and chondromatous sarcimas in Britisch Columbia - A review of 34 cases

Oral Oncol, 36 (2000), p. 27

8. D.S. Ruark, U.K. Schlehaider, J.P.M. Shah

Chondrosarcomas of the head and neck

World J Surg, 16 (1992), p. 1010

9. P.A. Webber, S.S. Hussain, G.J. Radcliffe

Cartilaginous neoplasms of the head and neck (a report on four cases)

J Laryngol Otol, 100 (1986), p. 615

10.S.R. Gadwal, J.C. Fanburg-Smith, F.H. Gannon, et al.

Primary chondrosarcoma of the head and neck in pediatric patients

Cancer, 88 (2000), p. 2181

11.G. Sammartino, G. Marenzi, M.H. Candace, et al. 
Chondrosarcoma of the jaw: A closer look at ists management

J Oral Maxillofac Surg, 66 (2008), p. 2349

12. K. Saito, K.K. Unni, P.C. Wollan, et al.

Chondrosarcoma of the jaw and the facial bones

Cancer, 76 (1995), p. 1550

13. F.L. Hackney, S.B. Aragon, T.B. Aufdemorte, et al.

Chondrosarcoma of the jaws: Clinical findings, histopathology and treatment

Oral Surg Oral Med Oral Pathol, 1 (1991), p. 139

14. S. Murayama, I. Suzuki, M. Nagase, et al.

Chondrosarcoma of the mandible: Report of a case and a survey of 23 cases in Japanese literature

J Craniomaxillofac Surg, 16 (1988), p. 287

15. H. Reychler

Cartilaginous tumors of the jaw

Rev Stomatol Chir Maxillofac, 89 (1988), p. 321

16. N. Zachariades, E. Vairaktaris, M. Mezitis, et al.

Chondrosarcoma of the orofacial region: Review of the literature and report of two cases

Rev StomatolChirMaxillofac, 88 (1987), p. 382

17. R.P. Gingrass

Chondrosarcoma of the mandibular joint: Report of a case

J Oral Surg (Chic), 12 (1954), p. 61

18. V.C. Lanier Jr, L. Rosenfeld, W. Ha III

Chondrosarcoma of the mandible

South Med J, 64 (1971), p. 711

19. K.J. Richter, N.S. Freeman, C.A. Quick

Chondrosarcoma of the temporomandibular joint: Report of case

J Oral Surg, 32 (1974), p. 777

20. G. Tullio, P. D'Errico

Il condrosarcoma della mandibola: Considerazioni cliniche ed istologiche

Ann Stomatol, 23 (1974), p. 191

21. C.J. Nortje, A.G. Farman, F.W. Grotepass, et al.

Chondrosarcoma of the mandibular condyle: Report of a case with special reference to radiographic features

Br J Oral Surg, 14 (1976), p. 101

22. H. Cadenat, R. Combelles, G. Fabert, et al.

Chondrosarcoma of the condyle (author's transl)

Rev Stomatol Chir Maxillofac, 80 (1979), p. 20

23. M.R. Morris, S.K. Clark, B.A. Porter, et al.

Chondrosarcoma of the temporomandibular joint: Case report

Head Neck Surg, 10 (1987), p. 113

24. J.J. Wasenko, S.A. Rosenbloom

Temporomandibular joint chondrosarcoma: CT demonstration

J Comput Assist Tomogr, 14 (1990), p. 1002 
25. D.W. Nitzan, Y. Marmary, O. Hasson, et al.

Chondrosarcoma arising in the temporomandibular joint: A case report and literature review

J Oral Maxillofac Surg, 51 (1993), p. 312

26. E. Sesenna, A. Tullio, S. Ferrari

Chondrosarcoma of the temporomandibular joint: A case report and review of the literature

J Oral Maxillofac Surg, 55 (1997), p. 1348

27. S.P. Mostafapour, N.D. Futran

Tumors and tumorous masses presenting as temporomandibular joint syndrome

Otolaryngol Head Neck Surg, 123 (2000), p. 459

28. Y. Kyoung-In, P. Min-Kyu, C.-H. Kim, et al.

Chondrosarcoma in the mandibular condyle: Case report

J Oral Kor J Maxillofac Surg, 34 (2008), p. 1

29. L. Gallego, L. Junquera, M.F. Fresno, et al.

Chondrosarcoma of the temporomandibular joint: A case report and review of the literature

Med Oral Patol Oral Cir Bucal, 14 (2009), p. E39

30. D.G. Finn, H. Goepfert, J.G. Batsakis

Chondrosarcoma of the head and neck

Laryngoscope, 94 (1984), p. 1539

31. J.G. Batsakis

Tumors of the Head and Neck

Williams \& Wilkins, Baltimore, MD (1979), pp. 383-387

32. H.L. Evans, A.G. Ayala, M.M. Romsdahl

Prognostic factors in chondrosarcoma of bone: A clinicopathologic analysis with emphasis on histologic grading

Cancer, 40 (1977), p. 818

33. B. Cohen, C.J. Smith

Chondrosarcoma of the mandible

Ann R Coll Surg, 32 (1963), p. 303

34. M.R. Molla, N. Ijuhin, T. Sugata, et al.

Chondrosarcoma of the jaws: Report of two cases

J Oral MaxillofacSurg, 45 (1987), p. 453

35. S.R. Aziz, A.R. Miremadi, J.C. McCabe

Mesenchymal chondrosarcoma of the maxilla with diffuse metastasis: Case report and literature review

J Oral Maxillofac Surg, 60 (2002), p. 931

36. E.R. Carlson, T. Panella, J.D. Holmes

Sarcoma of mandible

J Oral Maxillofac Surg, 62 (2004), p. 81

37. N. Penel, C. Van Haverbeke, E. Lartigau, et al.

Head and neck soft tissue sarcomas of adult: Prognostic value of surgery in multimodal therapeutic approach

Oral Oncol, 40 (2004), p. 890

38. G.E. Garrington, W.K. Collett

Chondrosarcoma: II. Chondrosarcoma of the jaws: Analysis of 37 cases

J Oral Pathol, 17 (1988), p. 12 
39. J. Bickels, I. Meller, B.M. Shmookler, et al.

The role and biology of cryosurgery in the treatment of bone tumors: A review

Acta Orthop Scand, 70 (1999), p. 308

40. R.C. Marcove, P.B. Stovell, A.G. Huvos, et al.

The use of cryosurgery in the treatment of low and medium grade chondrosarcoma: A preliminary report Clin Orthop Relat Res, 122 (1977), p. 147

41. R. Veth, B. Schreuder, H. van Beem, et al.

Cryosurgery in aggressive, benign, and low-grade malignant bone tumors

Lancet Oncol, 6 (2005), p. 25 